\title{
A mutual activation loop between breast cancer cells and myeloid-derived suppressor cells facilitates spontaneous metastasis through IL-6 trans-signaling in a murine model
}

Keunhee Oh ${ }^{1,2,3^{*}+}$, Ok-Young Lee ${ }^{1,2+}$, Suh Youn Shon ${ }^{1}$, Onyou Nam ${ }^{1,2}$, Po Mee Ryu ${ }^{1}$, Myung Won Seo ${ }^{1,3}$ and Dong-Sup Lee Le, $^{1,3^{*}}$

\begin{abstract}
Introduction: Tumor cell interactions with the microenvironment, especially those of bone-marrow-derived myeloid cells, are important in various aspects of tumor metastasis. Myeloid-derived suppressor cells (MDSCs) have been suggested to constitute tumor-favoring microenvironments. In this study, we elucidated a novel mechanism by which the MDSCs can mediate spontaneous distant metastasis of breast cancer cells.

Methods: Murine breast cancer cells, 4T1 and EMT6, were orthotopically grafted into the mammary fat pads of syngeneic BALB/c mice. CD11 b $\mathrm{Gr}^{+} 1^{+}$MDSCs in the spleen, liver, lung and primary tumor mass were analyzed. To evaluate the role of MDSCs in the distant metastasis, MDSCs were depleted or reconstituted in tumor-bearing mice. To evaluate whether MDSCs in the metastasizing tumor microenvironment affect breast cancer cell behavior, MDSCs and cancer cells were co-cultivated. To investigate the role of MDSCs in in vivo metastasis, we blocked the interactions between MDSCs and cancer cells.

Results: Using a murine breast cancer cell model, we showed that murine breast cancer cells with high IL-6 expression recruited more MDSCs and that the metastasizing capacity of cancer cells paralleled MDSC recruitment in tumor-bearing mice. Metastasizing, but not non-metastasizing, tumor-derived factors induced MDSCs to increase IL-6 production and full activation of recruited MDSCs occurred in the primary tumor site and metastatic organ in the vicinity of metastasizing cancer cells, but not in lymphoid organs. In addition, tumor-expanded MDSCs expressed Adam-family proteases, which facilitated shedding of IL-6 receptor, thereby contributing to breast cancer cell invasiveness and distant metastasis through IL-6 trans-signaling. The critical role of IL-6 trans-signaling was confirmed in both the afferent and efferent pathways of metastasis.

Conclusion: In this study, we showed that metastasizing cancer cells induced higher MDSCs infiltration and prompted them to secret exaggerated IL-6 as well as soluble IL-6R $\alpha$, which, in turn, triggered a persistent increase of pSTAT3 in tumor cells. This potential tumor-MDSC axis involving IL-6 trans-signaling directly affected breast cancer cell aggressiveness, leading to spontaneous metastasis.
\end{abstract}

Keywords: Myeloid-derived suppressor cell (MDSC), Breast cancer cell, Metastasis, IL-6 trans-signaling

\footnotetext{
*Correspondence: keunhee1@snu.ac.kr; dlee5522@snu.ac.kr

† Contributed equally

'Laboratory of Immunology and Cancer Biology, Department of Biomedical

Sciences, Seoul National University College of Medicine, 103 Daehak-ro

Jongno-gu, Seoul 110-799, Republic of Korea

Full list of author information is available at the end of the article
} 


\section{Introduction}

Breast cancer is the leading cause of cancer-associated death in women worldwide [1]. Despite recent improvements in early detection and effective adjuvant chemotherapies, about one-third of patients with early disease will relapse with distant metastasis [2]. Metastasis of breast cancer remains a largely incurable disease and is the major cause of mortality among breast cancer patients [3]. Cancer metastasis is a complex process comprising dissociation of cancer cells from the bulk tumor, invasion of the neighboring tissue, intravasation, transport through the vascular system, extravasation, engraftment of disseminated cells and, finally, outgrowth of micrometastases [4]. In our previous study, orthotopically grafted human breast cancer cells expressing high levels of IL-6, but not those with low levels of IL-6, spontaneously metastasized to the lung and liver in immunocompromised NOD $/ \mathrm{scid} / \gamma_{\mathrm{c}}$-deficient (NOG) mice [5]. IL-6 signaling in cancer cells themselves imbued them with cancer stem cell properties and epithelial-tomesenchymal transition (EMT) phenotypes, which facilitate cancer cell invasion into the surrounding tissue and blood vessels, and cause distant metastasis [5,6]. In addition, IL-6 is known to be an important mediator of the expansion and recruitment of myeloid-derived suppressor cells (MDSCs) $[7,8]$.

MDSCs are a heterogeneous population of cells comprising immature cells of monocyte or granulocyte lineage. They expand dramatically under conditions such as trauma, tumor growth and various chronic inflammatory disorders, including infection, sepsis and immunization $[7,8]$. Originally described as suppressive myeloid cells, thus-expanded MDSCs negatively regulate immune responses through multiple contact-dependent and -independent pathways [8,9]. Nitrosylation of T cell receptors (TCRs) and CD8 molecules leads to defective cytotoxic $\mathrm{T}$ cell $(\mathrm{CTL})$ responses, rendering the cells unresponsive to antigen-specific stimulation [10]. Shortage of L-arginine due to arginase I activity in MDSCs inhibits $\mathrm{T}$ cell proliferation by several mechanisms [11]. Nitrous oxide (NO) and transforming growth factor $-\beta$ (TGF- $\beta$ ) produced by MDSCs induced further immunosuppressive microenvironments favoring tumor growth [7-9]. In addition to the abovementioned immunosuppressive functions, MDSCs actively formulate microenvironments favoring the generation and survival of cancer cells in association with chronic inflammation. Induced expression of IL- $1 \beta$ in gastric epithelial cells induces the recruitment of MDSCs and leads to gastric inflammation and cancer, while activation of nuclear factor-kappa B (NF- $\kappa \mathrm{B})$ in MDSCs is strongly associated with carcinogenesis [12]. MDSCs have been suggested to facilitate cancer cell metastasis through their immunosuppressive activities $[8,13,14]$. Recently, cancerderived remote signals were shown to induce the accumulation of myeloid cells including MDSC populations in putative metastatic sites before migrating cancer cells arrived, forming a 'pre-metastatic niche', which aided extravasation of migrating cancer cells and facilitated new blood vessel formation [15-17]. Accumulating evidence shows that tumor-derived factors and tumor-cellsignaling mediators, such as Hsp72 and S1pr1, activate MDSCs to potentiate their immunosuppressive functions or increase the recruitment and colonization of these cells into pre-metastatic tissues [18,19]. Increased circulating MDSCs in breast cancer patients has been shown to be correlated with clinical cancer stage and metastatic tumor burden [20,21]. However, the evidence for the direct roles of cancer cell-exposed MDSCs in enhancing cancer cell aggressiveness, leading to spontaneous metastasis of these cells, from their invasion into the surrounding tissue and vascular system to their colonization of the target organ and the underlying mechanisms is either missing or merely circumstantial.

We questioned whether MDSCs activated by cancer cells directly increase breast cancer aggressiveness leading to spontaneous distant metastasis. To adequately evaluate the mutual interaction of breast cancer cells and inflammatory cells including MDSCs, we utilized murine models in which breast cancer cells were orthotopically grafted into immunocompetent syngeneic mice [22]. We found that murine breast cancer cells with high IL-6 expression recruited more MDSCs and that the metastasizing capacity of cancer cells paralleled MDSC recruitment in tumor-bearing mice. Depletion and addition of MDSCs from tumor-bearing mice, respectively, reduced and increased the distant metastasis of breast cancer cells. Metastasizing, but not nonmetastasizing, cancer cells activated MDSCs, increasing their expression and secretion of both IL- 6 and soluble IL-6R $\alpha$, and facilitated breast cancer cell invasiveness and distant metastasis through IL-6 trans-signaling, acting both in afferent and efferent metastatic pathways. Thus, we provide evidence that breast cancer cells and MDSCs formed a synergistic mutual feedback loop and that thus-potentiated MDSCs directly affect breast cancer cell aggressiveness, leading to spontaneous metastasis.

\section{Methods \\ Animals}

BALB/c mice were purchased from the Jackson Laboratory (Bar Harbor, MA, USA). Experiments involving mice were approved by the Institutional Animal Care and Use Committee of Seoul National University (authorization no. SNU05050203). 


\section{Cell lines}

The mouse breast carcinoma cell lines 4T1 (ATCC CRL-2539) and EMT6 (ATCC CRL-2755) were purchased from the American Type Culture Collection (Manassas, VA, USA) and maintained in RPMI 1640 (WelGENE, Daegu, South Korea) supplemented with $10 \%$ heat-inactivated fetal bovine serum (FBS) (GIBCO, Grand Island, NY, USA) and 1\% antibiotics (100 U/ml penicillin and $100 \mu \mathrm{g} / \mathrm{ml}$ streptomycin) at $37^{\circ} \mathrm{C}$ in a humidified 5\% $\mathrm{CO}_{2}$ atmosphere. IL-6-expressing EMT6 cells (EMT6_IL-6 cells) were established by transfection with the pcDNA3.1_IL-6 construct using PromoFectin (PromoKine, Heidelberg, Germany), according to the manufacturer's instructions. Control cells were transfected with the pcDNA3.1 vector only. Stably transfected clones were established by selection with G418 (Sigma-Aldrich, St. Louis, MO, USA) at a concentration of $500 \mu \mathrm{g} / \mathrm{ml}$ for three weeks. IL-6-expressing EMT6 (EMT6_IL-6) clones were selected by ELISA. IL-6-knockdown 4T1 cells (4T1_shIL-6 cells) and Stat3-knockdown 4T1 cells (4T1_shSTAT3 cells) were established using the lentiviral vectors containing the shRNA (Santa Cruz Biotechnology, Santa Cruz, CA, USA). Cells were infected with the shIL- 6 or shSTAT3 virus and cultured in the presence of puromycin, and IL-6-knockdown 4T1 (4T1_shIL-6) and Stat3-knockdown 4T1 (4T1_shStat3) clones were selected by ELISA and Western blotting, respectively.

\section{Tumor models}

4T1 and EMT6 cells $\left(1 \times 10^{5} /\right.$ mouse $)$ were injected into the mammary fat pads of BALB/c mice. Tumor growth was monitored every other day thereafter. At 26 or 29 days after injection, the mice were euthanized and primary tumor masses, livers and lungs were fixed in $4 \%$ paraformaldehyde (PFA) for 24 hours and embedded in paraffin. Sections $(5 \mu \mathrm{m})$ were stained with $\mathrm{H} \& \mathrm{E}$ for histopathological analysis. Numbers of tumor masses in the liver and lungs were determined under a dissecting microscope before fixing with $4 \%$ PFA. To deplete MDSCs, mice were intraperitoneally injected with $100 \mu \mathrm{g}$ of anti-Gr-1 antibody (RB6-8C5, eBioscience, San Diego, CA) or control Rat immunoglobulin G 1 (IgG1) twice a week, starting three days after $4 \mathrm{~T} 1$ cell injection. To block IL-6 trans-signaling in the afferent pathways of metastasis, 4T1 cells were injected into the mammary fat pads and gp130-Fc (R\&D Systems, Minneapolis, MN, USA) was administered continuously using an osmotic mini-pump (5 or $10 \mu \mathrm{g}$ for 14 days; Alzet, Cupertino, CA, USA). To block IL-6 trans-signaling in the efferent pathways of metastasis, 4T1 cells were injected intravenously into BALB/c mice and mice were intravenously injected with gp130-Fc (2.5 $\mu \mathrm{g} /$ mouse $) 4$ four days after cell injection.

\section{Flow cytometry and MDSC isolation}

To analyze MDSCs, mice were sacrificed 19 or 21 days after cancer cell injection. Mononuclear cells from the liver, lungs and primary tumor masses were isolated by Percoll (Amersham, GE healthcare, Buckinghamshire, UK) gradient centrifugation. Tissues were digested with collagenase D (1 mg/ml, Invitrogen, Carlsbad, CA, USA) and DNase I (0.5 U/ml, Sigma-Aldrich) for one hour at $37^{\circ} \mathrm{C}$. Cells were suspended in $30 \%$ Percoll, layered onto the top of a $70 \%$ Percoll gradient and centrifuged $(800 \times g$, 20 minutes). The interface was retained. Next, the cells were incubated with mAbs to mouse CD11b, Ly6C and Gr-1 that were conjugated to phycoerythrin, PerCP-Cy5.5, or allophycocyanin (eBioscience). They were then analyzed using a FACSCalibur flow cytometer (BD Biosciences, San Jose, CA, USA) and FlowJo software (Tree Star, Ashland, OR, USA). To isolate splenic MDSCs from naïve or tumor-bearing mice, splenocytes were prepared and labeled with phycoerythrin-conjugated anti-CD11b mAb (BD Pharmingen, San Jose, CA, USA) and allophycocyaninconjugated anti-Gr-1 mAb (eBioscience). CD11b ${ }^{+} \mathrm{Gr}-1^{+}$ MDSCs were purified using a FACS Aria cell sorter (BD Biosciences). The purity after sorting was greater than $95 \%$.

\section{Tumor and MDSC conditioned medium preparation}

EMT6 cells $\left(1 \times 10^{4}\right)$ and 4 T1 cells $\left(1 \times 10^{4}\right)$ were incubated for 72 hours on a 24-well plate and the culture supernatants were collected. To obtain MDSC CM, FACS-sorted splenic MDSCs $\left(4 \times 10^{5}\right)$ were cultured for 24 hours. 4T1/MDSC-CM and EMT6/MDSC-CM were prepared by cultivating MDSCs $\left(4 \times 10^{5}\right)$ in $50 \%(\mathrm{v} / \mathrm{v})$ 4T1-CM or EMT6-CM for 24 hours. A volume of 4T1/ MDSC-CM containing $1 \mathrm{ng}$ of IL- 6 , or the same volume of EMT6/MDSC-CM or MDSC-CM, was added to the 4T1 and EMT6 cell cultures. To some cultures, the following signaling inhibitors were added; Stat3 inhibitor peptide (1 $\mu \mathrm{M}$; Millipore, Billerica, MA, USA), PI3K inhibitor (LY294002, $10 \mu \mathrm{M}$; Calbiochem, Billerica, MA, USA), NF- $\kappa$ B inhibitor (Bay-117082, $10 \mu \mathrm{M}$; Calbiochem), JNK inhibitor (SP600125, $10 \mu \mathrm{M}$; Calbiochem), p38 MAPK inhibitor (SB403250, $10 \mu \mathrm{M}$; Cell Signaling, Danvers, MA, USA), and ERK inhibitor (PD98059, $10 \mu \mathrm{M}$; Calbiochem).

\section{Immunofluorescence microscopy}

Tissues were fixed in 4\% PFA and embedded in paraffin. Sections were stained with $\mathrm{H} \& \mathrm{E}$ for histopathological analysis. To investigate IL-6, IL-6R $\alpha$, and Adam 17 expression levels in MDSCs, sections were stained with anti-Gr-1 mAb and other appropriate antibodies. The following primary antibodies were used: anti-mouse IL-6 (Abcam, Cambridge, MA, USA), anti-mouse IL-6R $\alpha$ (Santa Cruz Biotechnology, Santa Cruz, CA, USA), 
anti-mouse Adam17 (Abcam) and anti-mouse Gr-1 (eBioscience). The following secondary antibodies were used: Alexa 488-conjugated anti-rabbit IgG (Invitrogen) and Alexa 594-conjugated anti-rat IgG (Invitrogen). Image acquisition and processing was performing using a confocal fluorescence microscope (Olympus, Center Valley, PA, USA) and an FV10-ASW 2.0 Viewer (Olympus).

\section{ELISA}

EMT6 and 4T1 cells were plated on a 24-well plate $(1 \times$ $10^{4} /$ well). The cells were permitted to grow for 24 or 48 hours. Supernatants were collected and assayed for IL- 6 and soluble IL-6R $\alpha$ levels by ELISA. For IL- 6 detection, anti-mouse IL-6 (eBioscience) was used as the capture antibody, biotinylated anti-mouse IL-6 (eBioscience) in $0.1 \%$ BSA in PBS/T as the detection antibody and recombinant IL-6 (eBioscience) as the standard. To detect soluble IL-6R $\alpha$, we used anti-mouse IL-6R $\alpha$ (R\&D Systems) as the capture antibody, biotinylated anti-mouse IL-6R $\alpha$ (R\&D Systems) as the detection antibody and recombinant IL-6R $\alpha$ (R\&D Systems) as the standard.

\section{RNA analysis}

RNA was isolated from sorted splenic MDSC using the RNeasy kit (QIAGEN; 74104, Hilden, Germany). cDNA was generated from $1 \mu \mathrm{g}$ of total RNA by reverse transcriptase from Moloney Murine Leukemia Virus (M-MLV) (TAKARA, Shiga, Japan), and subjected to PCR. The following primer pairs were used for PCR: GAPDH, 5'-GTCAGTGGTGGACCTGACCT-3' and 5'-AGGGGT CTACATGGCAACTG-3'; IL-6, 5'-GACAAAGCCAG AGTCCTTCAGAG-3' and 5'-CTAGGTTTGCCGAGTAG ATCTC-3'. PCR products were analyzed by $1.5 \%$ agarose gel electrophoresis.

\section{Western blot analysis}

Cells were harvested in lysis solution containing $50 \mathrm{mM}$ Tris/ $\mathrm{HCl}$ ( $\mathrm{pH} 7.6), 1 \% \mathrm{NP} 40,150 \mathrm{mM} \mathrm{NaCl}, 2 \mathrm{mM}$ EDTA, $100 \mu \mathrm{M}$ PMSF, a protease inhibitor cocktail (Roche Applied Science, Basel, Switzerland), and a phosphatase inhibitor (Sigma-Aldrich). After incubation on ice for 30 minutes, cellular debris was removed by centrifugation $\left(10\right.$ minutes, $\left.4^{\circ} \mathrm{C}\right)$. Proteins $(10 \mu \mathrm{g})$ were separated by SDS-PAGE and then transferred to a polyvinylidene difluoride membrane. After blocking with 5\% skim milk, the membranes were probed with an appropriate antibody. Blots were developed with an enhanced chemiluminescence Western blotting detection system (Amersham, GE Healthcare, Buckinghamshire, UK). The following antibodies were used: anti- $\beta$-actin (Sigma-Aldrich), anti-phospho-Stat3 (Tyr705) (Cell Signaling, Danvers, MA, USA), anti-Stat3 (Santa Cruz Biotechnology), antiI- $\kappa$ B (Santa Cruz Biotechnology), anti-phospho-JNK
(Santa Cruz Biotechnology), anti-phospho-ERK (Santa Cruz Biotechnology), and anti-phospho-p38 (Cell Signaling).

\section{Invasion assay}

Matrigel matrix solution $\left(200 \mu \mathrm{g} / \mathrm{ml}\right.$, Matrigel ${ }^{\mathrm{TM}}$ Basement Membrane Matrix, BD Bioscience) was applied to each Transwell (Falcon, Franklin Lakes, NJ, USA). 4T1 cells $\left(5 \times 10^{4}\right)$ were seeded into the upper chamber of the Transwell and then the lower chamber was filled with collagen matrix $(5 \mu \mathrm{g} / \mathrm{ml})$. Invasion assays were carried out for 18 hours. Non-invading cells on top of the matrix were removed by rubbing with a moistened cotton swab. Invaded cells on the lower surface of the Matrigel matrix were fixed with $4 \%$ PFA and stained with $0.2 \%$ crystal violet. Cells were counted using ImageJ software (version 1.46).

\section{Statistical analyses}

The two-tailed Student's $t$-test was used to compare measurements for pairs of samples. Two-way analysis of variance (ANOVA) and Bonferroni post hoc testing were used to compare the tumor volumes of the two groups. The SPSS software (SPSS Inc.) was used for all statistical analyses.

\section{Results}

\section{Correlation of spontaneous distant metastasis of breast} cancer cells with MDSC recruitment

In our previous report, high IL-6-secreting human breast cancer cells revealed more aggressive phenotypes including enhanced distant metastasis [5] and recruited more inflammatory cells (our unpublished data) compared to the low IL-6 expressing cells. In another report, we also showed that damaged epithelial cells produced IL-6 and recruited inflammatory cells including neutrophils [23]. Thus, we assumed that IL-6 derived from cancer cells could affect the metastasis of cancer cells through inflammatory cell, including MDSC, recruitment. To elucidate the relationship between MDSC recruitment and distant metastasis of cancer cells, we created a murine breast cancer model using 4T1 and EMT6 breast cancer cells, which exhibit differential IL-6 expression [see Additional file 1, Figure S1]. 4T1 and EMT6 cells were orthotopically grafted into the mammary fat pads of syngeneic BALB/c mice. Primary tumor growth was slightly but significantly greater for EMT6 cells compared to 4T1 cells during the entire experimental period (Figure 1A). At 26 days after grafting, 4T1 cancer cells showed extensive lung metastasis, while EMT6 cancer cells showed no distant metastasis in the lung, liver, bone or brain (Figure 1B). IL-6-expressing 4T1 cell-bearing mice showed dramatic recruitment of $\mathrm{CD} 11 \mathrm{~b}^{+} \mathrm{Gr}-1^{+} \mathrm{MDSCs}$ in the spleen (a lymphoid organ), 


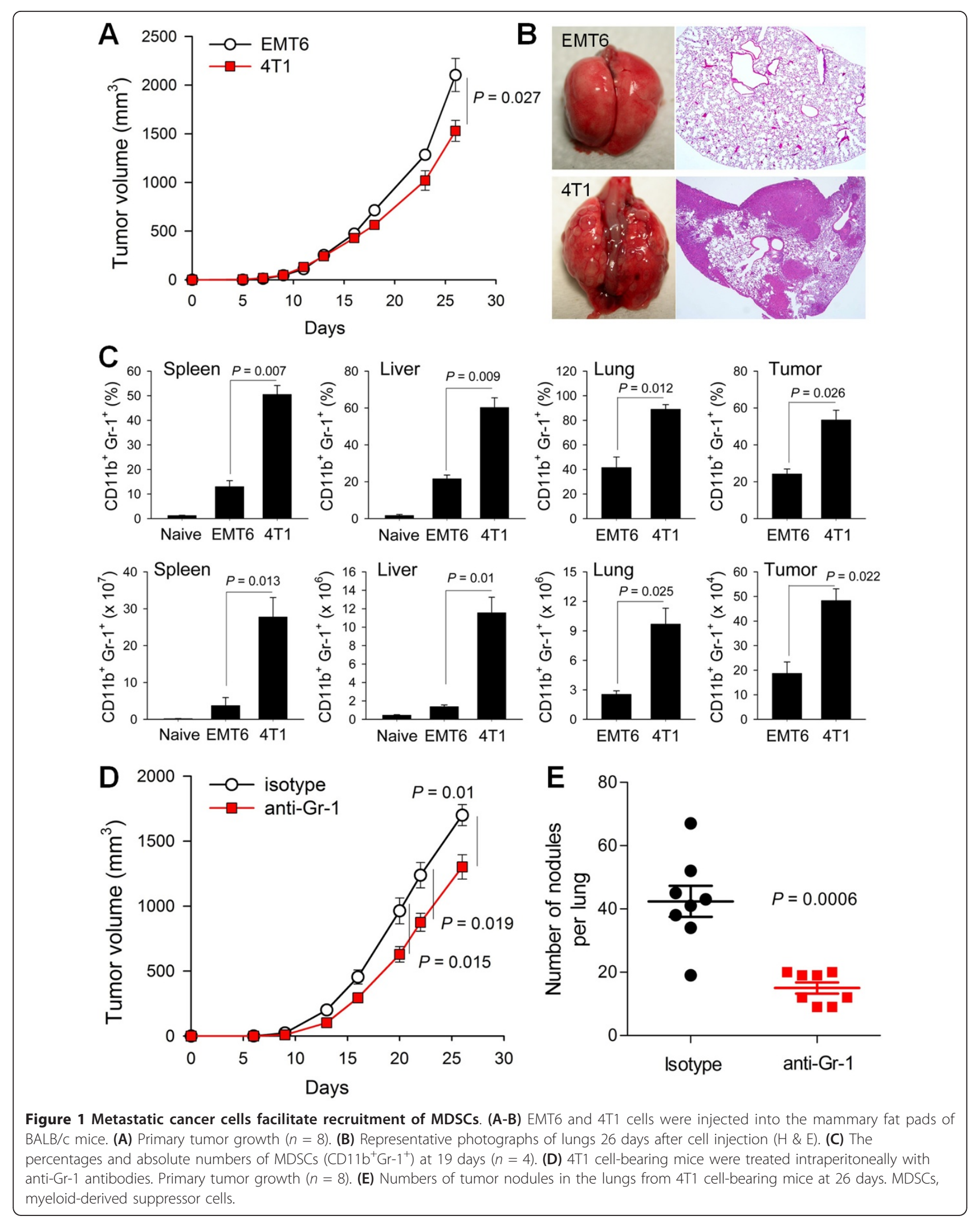


metastasizing organs (liver and lung) and primary tumor mass; the total number of MDSCs recruited was two to eight times higher in 4T1 cell-bearing mice than in EMT6 cell-bearing mice (Figure $1 \mathrm{C}$ and see Additional file 1, Figure S2). To further evaluate the role of MDSCs in the distant metastasis, the 4T1 cell tumor-bearing mice were depleted of MDSCs. Depletion of MDSCs reduced $4 \mathrm{~T} 1$ lung metastasis $(P=0.0006)$ and primary tumor growth in the mammary fat pads (Figure 1D and 1E). These results show that MDSCs that expanded and recruited in the tumor-bearing mice are critically associated with the distant metastasis of cancer cells.

\section{Induction of IL-6 expression facilitated MDSC recruitment} and increased their metastatic capacity

We next evaluated whether IL-6-mediated MDSC recruitment promoted the metastasis of EMT6 cancer cells. We stably transfected EMT6 cells with a vector encoding murine IL-6 (EMT6_IL-6) [see Additional file 1, Figure S3A]. EMT6_IL-6 cancer cells grafted into the mammary fat pads of syngeneic recipients recruited more MDSCs to the spleen, liver, lung and primary tumor mass compared to the control empty vector-transfected
EMT6 (EMT6_Con) cells (Figure 2A). The percentages and numbers of MDSCs recruited to these sites were comparable in EMT6_IL-6-bearing mice and 4T1 cellbearing mice (Figure 1B and see Additional file 1, Figure S3B). EMT6_IL-6 cells showed increased tumor growth compared to the control EMT6_Con cells (Figure 2B). However, unexpectedly, distant lung metastasis was only slightly increased in EMT6_IL-6 cell-bearing mice $(P=0.039)$ (Figure $2 C)$. Thus, we concluded that IL-6 secreted from breast cancer cells is an important and sufficient factor for MDSC expansion and recruitment, but that additional factors are required to facilitate the recruited MDSC-mediated metastasis of cancer cells.

To reconstitute a microenvironment that more closely resembles that of $4 \mathrm{~T} 1$ cell-bearing mice, we adoptively transferred splenic MDSCs from 4T1 cell-bearing mice into EMT6 cell-bearing mice. MDSC-transferred EMT6 cell-bearing mice showed reduced primary tumor growth in the mammary fat pads, and only slightly increased lung metastasis, compared to vehicle-treated EMT6 cell-bearing mice (Figure 2D). Thus, neither repeated transfer of splenic MDSCs from metastatic tumor-bearing mice nor overexpression of IL-6 was

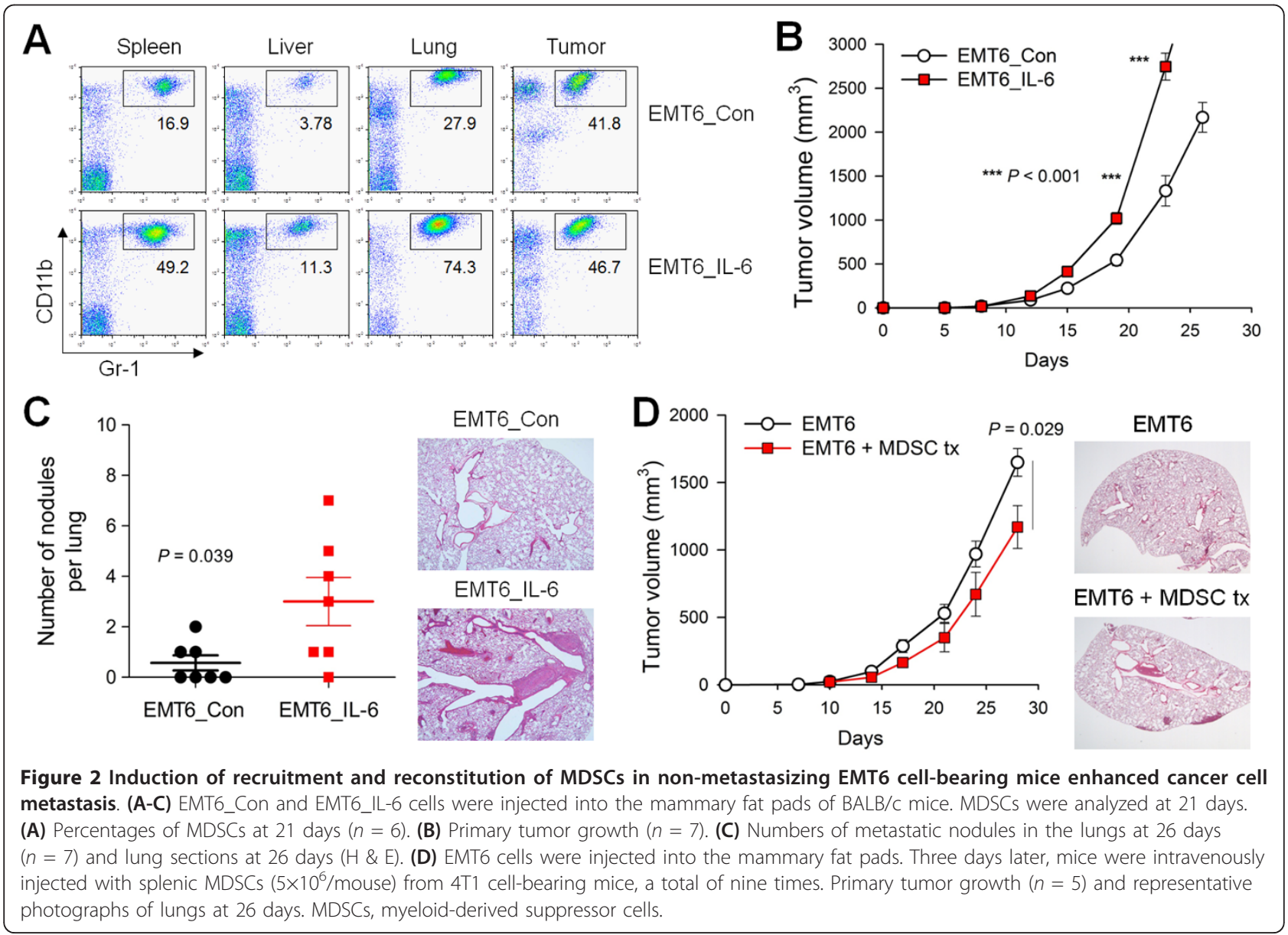


sufficient to confer on non-metastasizing EMT6 cancer cells a metastasizing capacity comparable to that of $4 \mathrm{~T} 1$ breast cancer cells. We assume that metastasizing cancer cells produce additional effects to potentiate the recruited MDSCs, thereby leading to distant metastasis.

\section{Metastasizing, but not non-metastasizing, breast cancer cells activated MDSCs}

To evaluate whether metastasizing, but not non-metastasizing, cancer cells further activate recruited MDSCs, we collected splenic MDSCs from naïve and tumorbearing mice and co-cultivated them with 4T1 and EMT6 cells. Splenic MDSCs co-cultured with 4T1 cells showed increased production of IL-6, irrespective of their source (naïve, EMT6 cell-bearing, or 4T1 cell-bearing mice), compared to those co-cultured with EMT6 cells (Figure 3A). 4T1 cells co-cultured with splenic MDSCs provided activated signals either in the same chamber (lower) or a different chamber (upper) in a
Transwell culture assay (Figure 3B), implying that contactindependent factors were important for activation of splenic MDSCs. To confirm the critical role of soluble factors derived from metastasizing breast cancer cells, conditioned media (CM) from breast cancer cells (4T1CM and EMT6-CM) were applied to splenic MDSC cultures. 4T1-CM, but not EMT6-CM, enhanced the production of IL- 6 by splenic MDSCs (Figure 3C). 4T1CM increased IL-6 transcription in splenic MDSCs from both 4T1cell- and EMT6 cell-bearing mice; EMT6-CM and recombinant IL- 6 only slightly induced the transcription of IL-6 [see Additional file 1 Figure S4]. Exposure of splenic MDSCs to 4T1-CM induced the activation of several signaling pathways, including Stat3, NF- $\kappa \mathrm{B}$, JNK, ERK and p38 pathways [see Additional file 1, Figure S5]. Using inhibitors of each pathway, we found that the $\mathrm{NF}-\kappa \mathrm{B}, \mathrm{JNK}$, and p38 signaling pathways were important in the production of IL- 6 by activated MDSCs (Figure $3 \mathrm{D})$. Importantly, confocal microscopic analysis of tissues

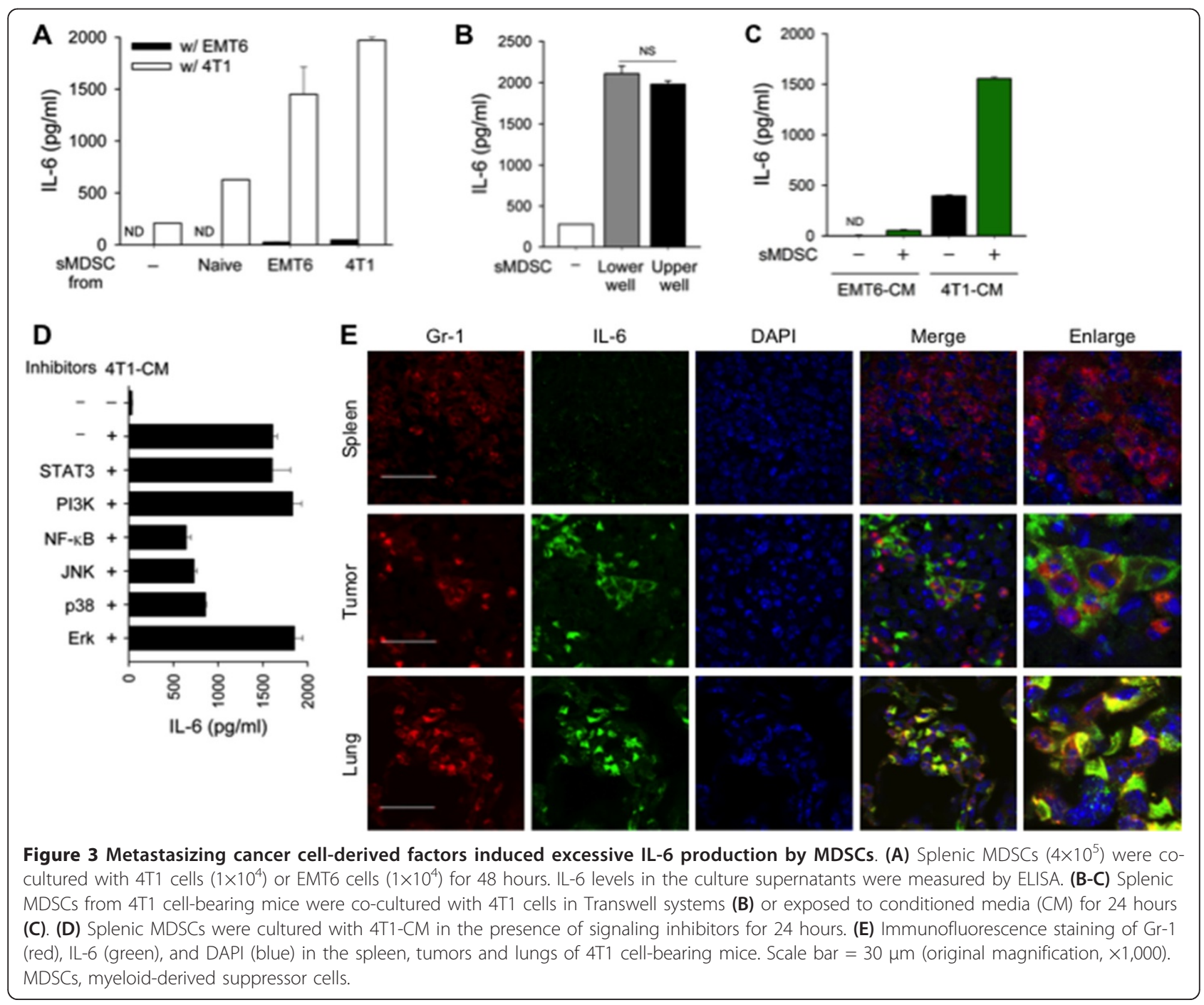


from 4T1 cell-bearing mice revealed that MDSCs inside the primary tumor and lung strongly expressed IL- 6 while those in spleen tissues from the same mice expressed little IL-6, but MDSCs in the primary tumor site of EMT6-bearing mice did not show increased expression of IL-6 (Figure 3E and see Additional file 1, Figure S6). In summary, metastasizing, but not non-metastasizing, tumor-derived factors induced MDSCs to produce more IL-6, and full activation of recruited MDSCs occurred in the primary tumor site and metastatic organs in the vicinity of metastasizing cancer cells.

\section{Activated MDSCs confer invasive potential on breast} cancer cells and stimulate distant metastasis through IL-6 trans-signaling

We next evaluated whether activated MDSCs in the metastasizing tumor microenvironment affect breast cancer cell behavior. We cultured 4T1 and EMT6 cells in CM from splenic MDSCs cultivated in the presence of 4T1-CM or EMT6-CM (4T1/MDSC-CM and EMT6/ MDSC-CM, respectively) (Figure 4A). 4T1 cells cultured with splenic MDSC-CM showed mild phosphorylation of Stat3. Moreover, 4T1 cells cultured with 4T1/MDSC$\mathrm{CM}$, but not EMT6/MDSC-CM, showed greatly increased Stat3 phosphorylation within 10 minutes (Figure 4B). Stat3 phosphorylation levels were increased for 48 hours in $4 \mathrm{~T} 1$ cells cultured in the presence of 4T1/MDSC-CM (Figure $4 \mathrm{C}$ and our unpublished data). Unlike 4T1/ MDSC-CM, however, 4T1-CM did not induce the persistent activation of STAT3 [see Additional file 1, Figure S7]. Similar results were obtained for $4 \mathrm{~T} 1$ cells co-cultured with splenic MDSCs, but not for 4T1 cells cultured in the presence of recombinant IL-6 (Figure 4D). These data suggest that IL-6 was important in inducing Stat3
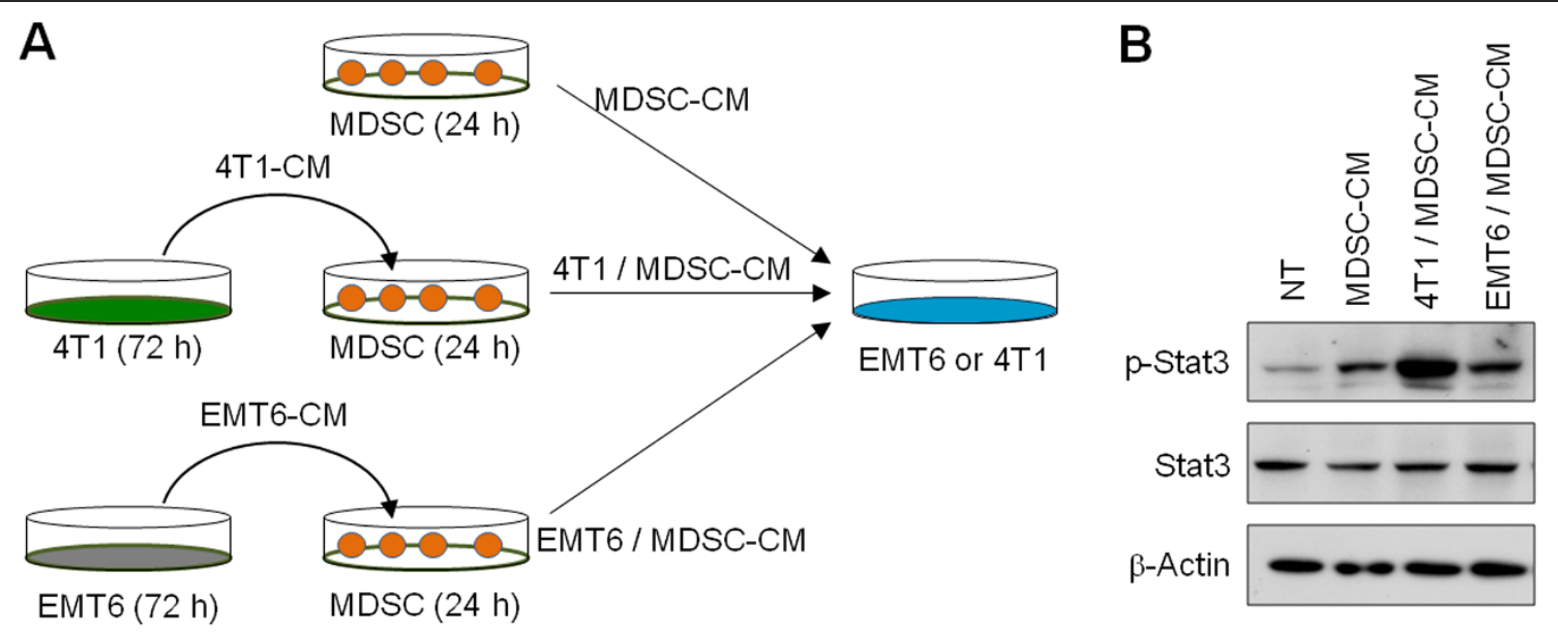

C

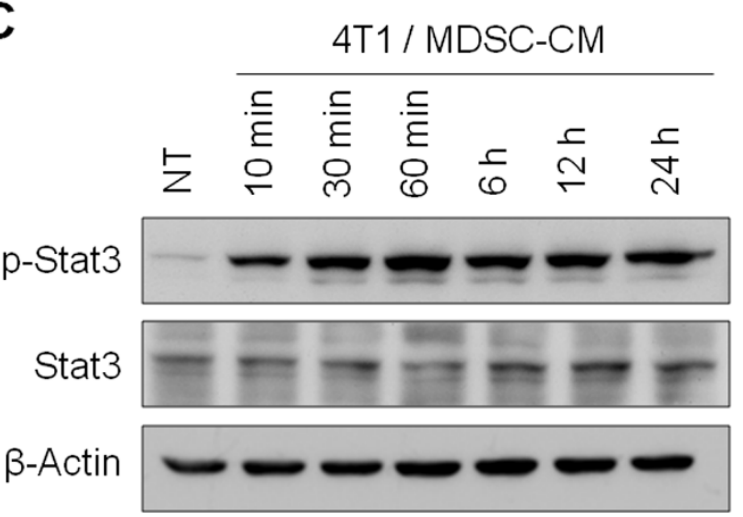

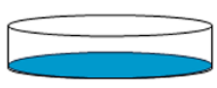

EMT6 or 4 T1



Figure 4 Stimulation of MDSCs with metastasizing 4T1 cell-derived factors induced persistent Stat3 phosphorylation in cancer cells (A) Splenic MDSCs from 4T1 cell-bearing mice were cultivated in the presence of 4T1-CM or EMT6-CM. The conditioned media (MDSC-CM, 4T1/ MDSC-CM, EMT6/MDSC-CM) were harvested and applied to 4T1 and EMT6 cancer cells. (B-C) Phospho-Stat3 and Stat3 levels in 4T1 cells exposed to each CM for 10 minutes (B) and for the indicated periods of time (C). (D) $4 \mathrm{~T} 1$ cells $\left(1 \times 10^{4}\right)$ were co-cultured with splenic MDSCs $\left(4 \times 10^{5}\right)$ from $4 \mathrm{~T} 1$ cell-bearing mice or recombinant mouse IL-6 $(1 \mathrm{ng} / \mathrm{ml})$. Phospho-Stat3 and Stat3 levels in $4 \mathrm{~T} 1$ cells were determined by Western blotting after the removal of MDSCs. CM, conditioned media; MDSCs, myeloid-derived suppressor cells. 
phosphorylation in 4T1 cells, but that factors other than IL-6 from tumor-infiltrating MDSCs were needed for persistent Stat3 phosphorylation.

The recent characterization of IL- 6 trans-signaling [24] suggests that tumor microenvironments may provide soluble IL-6R $\alpha$ as well as IL-6 to maximally induce cancer cell aggressiveness through highly augmented IL-6 signaling, which is implicated in tumor cell survival, cancer stem cell characteristics and EMT phenotypes important for successful distant metastasis of cancer cells $[5,6]$. To investigate which cells in the tumor microenvironment provide soluble IL-6R $\alpha$, we measured levels of soluble IL-6R $\alpha$ secreted from ex vivo-cultured splenic MDSCs from naïve, EMT6 cell-bearing, and 4T1 cell-bearing mice and 4T1 cancer cells. MDSCs from tumor-bearing mice generated more soluble IL-6R $\alpha$ compared to 4T1 cells. Compared to those from naïve and EMT6 cell-bearing mice, splenic MDSCs from 4T1 cell-bearing mice produced more soluble IL-6R $\alpha$ in ex vivo culture (Figure 5A and see Additional file 1, Figure S8). In contrast, splenic MDSCs from naïve, EMT6 cell-bearing and 4T1 cell-bearing mice expressed similar levels of surface IL-6R $\alpha$ chain (Figure 5B).

Production of soluble IL-6R $\alpha$ involves cell surfaceassociated proteases. Adam family proteases, especially Adam10 and Adam17, have been implicated in IL-6 trans-signaling $[25,26]$. Non-stimulated splenic MDSCs from 4T1 cell-bearing mice expressed increased levels of

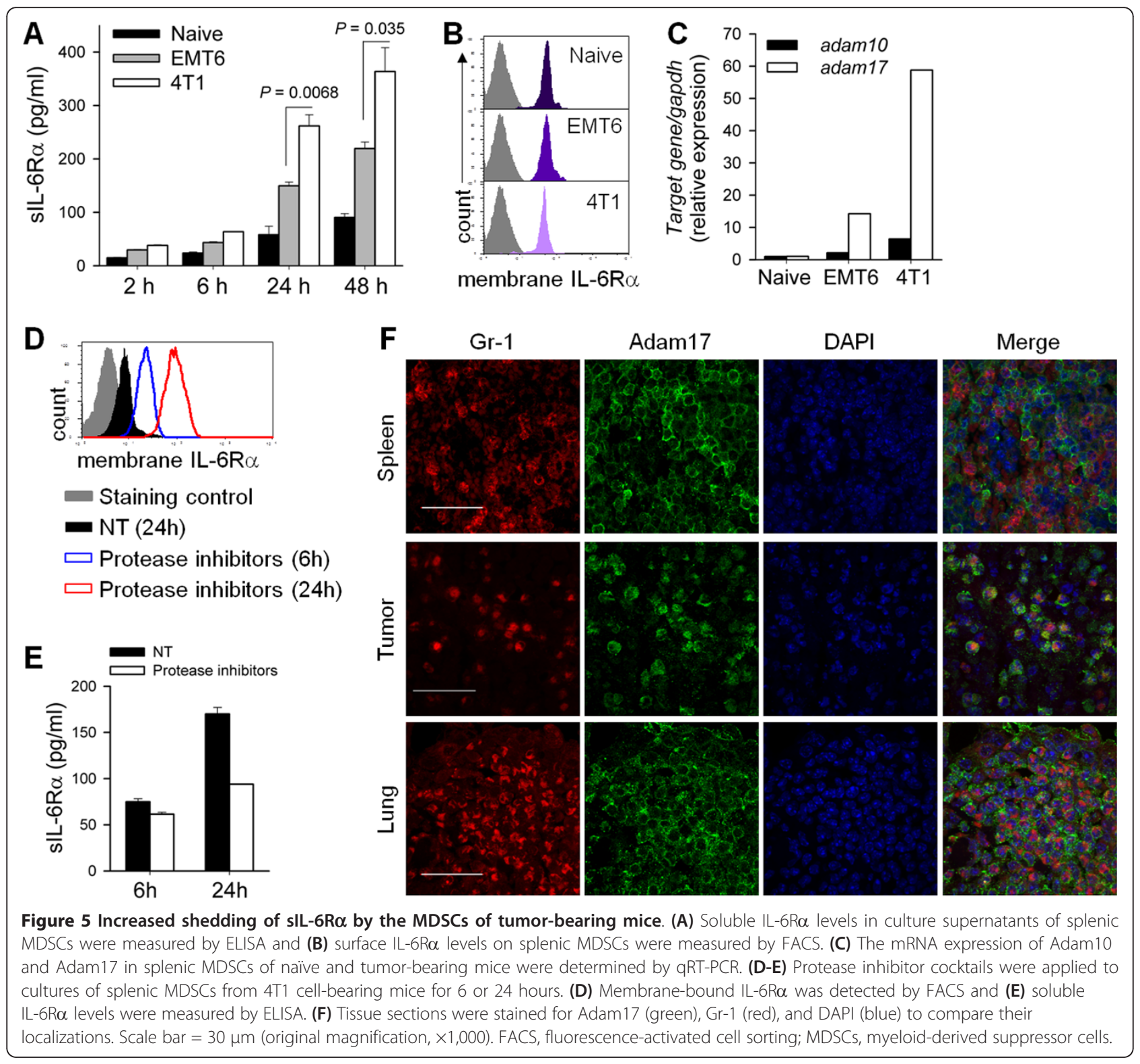


both Adam 10 and Adam 17 compared to MDSCs from EMT6 cell-bearing mice and naïve mice (Figure 5C). When we cultivated splenic MDSCs from 4T1 cell-bearing mice in the presence of protease inhibitors, levels of the membrane-bound form of IL-6R $\alpha$ increased and those of soluble IL-6R $\alpha$ levels decreased (Figure 5D and 5E). To further evaluate the critical role of ADAM family proteases in IL-6R $\alpha$ shedding, we also utilized a more specific protease inhibitor, TAPI-2, an inhibitor of ADAM family proteases including ADAM17. TAPI-2, as well as a broadspectrum protease inhibitors cocktail, decreased shedding of surface IL-6R $\alpha$. [see Additional file 1, Figure S9]. To confirm the expression of Adam17 and IL-6R $\alpha$ by MDSCs in vivo, we analyzed spleen tissues, primary tumor masses and metastatic lesions in the lungs from 4T1 cell-bearing mice. Confocal microscopy showed that MDSCs in the spleen, primary tumor sites and lung expressed increased levels of Adam 17 and IL-6R $\alpha$ on their surfaces in 4T1 cell-bearing mice compared to those in EMT6 cell-bearing mice (Figure 5F and see Additional file 1, Figure S10). Thus MDSCs that were expanded and recruited in the metastasizing tumor-bearing mice were already capable of soluble IL-6R $\alpha$ production, even in the spleen, a site remote from the metastasizing cancer cells. Taken together with the increased IL-6 levels only in the vicinity of metastasizing tumor cells, these findings suggest that IL-6 trans-signaling occurs preferentially in primary tumor sites and the metastatic lung but not in the spleen.

To evaluate whether IL- 6 trans-signaling is important for activation of $4 \mathrm{~T} 1$ breast cancer cells, we cultivated $4 \mathrm{~T} 1$ cells in the presence of IL- 6 and/or soluble IL-6R $\alpha$ and evaluated the individual and combined effects of a blocking anti-IL-6R antibody (which blocks both conventional IL-6 signaling and IL-6 trans-signaling) and a gp130-Fc fusion protein (which only blocks IL-6 transsignaling). When applied individually, IL-6, but not soluble IL-6R $\alpha$, increased Stat3 phosphorylation in $4 \mathrm{~T} 1$ cells. Treatment with both IL- 6 and soluble IL-6R $\alpha$ further increased the phosphorylation of Stat3, implying that IL- 6 trans-signaling functioned in $4 \mathrm{~T} 1$ cell activation (Figure 6A). Inhibition of IL-6 trans-signaling with gp130-Fc blocked Stat3 phosphorylation as efficiently as the IL-6R antibody (Figure 6A). To further confirm the role of IL- 6 trans-signaling in the interaction of breast cancer cells and MDSCs, 4T1 cells were cultured in the presence of 4T1/MDSC-CM. gp130-Fc fusion protein treatment inhibited Stat3 phosphorylation in 4T1 cells to an extent comparable to IL-6R antibody treatment (Figure 6B). The enhanced IL-6 signaling mediated by the cancer cell-MDSC interaction augmented 4T1 breast cancer cell aggressiveness. 4T1 cells cultivated with 4T1/MDSC-CM showed exaggerated invasiveness in a Matrigel invasion assay, a response that was blocked by gp130-Fc treatment (Figure 6C). To investigate the role of IL-6 trans-signaling in in vivo metastasis, we administered gp130-Fc to the tumor-bearing mice. Continuous infusion of gp130-Fc (5 or $10 \mu \mathrm{g} / \mathrm{ea} / 14$ days), starting from the day following cancer cell injection, reduced primary tumor growth in the mammary fat pads (Figure 6D) and lung metastasis in a dose-dependent manner (Figure 6E). These findings support the critical role of IL-6 trans-signaling in breast cancer cell invasiveness and metastasis in vivo. As increased IL-6 trans-signaling in $4 \mathrm{~T} 1$ cell-bearing mice was suggested to occur in the primary tumor sites and metastatic lung (Figure 3E), we evaluated whether increased IL- 6 trans-signaling in the lung also affected the efferent phase of cancer cell metastasis. Treatment with gp130-Fc $(2.5 \mu \mathrm{g} /$ bolus, i.v. $)$ on day 4 after intravenous cancer cell injection decreased the lung metastasis of $4 \mathrm{~T} 1$ cancer cells compared to vehicle-treated controls (Figure 6F).

Finally, to confirm whether the strong and persistent Stat3 phosphorylation in MDSC-potentiated cancer cells is crucial to spontaneous tumor metastasis, we generated Stat3-knockdown 4T1 (4T1_shStat3) cells [see Additional file 1, Figure S11]. 4T1_shSTAT3 cells revealed similar levels of IL-6 production and MDSC recruitments compared to 4T1_Con cells (data not shown). Greatly increased invasiveness in a Matrigel invasion assay was observed in control 4T1 (4T1_Con) cells, but not in 4T1_shStat3 cells, after treatment with 4T1/MDSC-CM, although reduced Stat3 expression itself had no effect on cancer cell invasiveness (Figure 7A and 7B). Primary tumor growth in the mammary fat pads was reduced in 4T1_shStat3 cell-bearing mice compared to 4T1_Con cell-bearing mice, while the reduction in distant lung metastasis was more dramatic in 4T1_shStat3 cell-bearing mice which exhibited few metastases (Figure 7C and 7D).

\section{Discussion}

In this study, we showed that IL-6 derived from metastasizing murine breast cancer cells recruited MDSCs and tumor-expanded MDSCs expressed Adam-family proteases, which facilitated shedding of IL- 6 receptors, thereby providing sIL-6R $\alpha$. In addition, factors other than IL-6, released from the cancer cells, promoted IL-6 production from recruited MDSCs in the vicinity of cancer cells. MDSC-derived IL-6 and sIL-6R $\alpha$ induced persistent activation of STAT3 and increased invasiveness of breast cancer cells via an IL-6 trans-signaling mechanism. This IL-6 trans-signaling also increased distant metastasis in vivo. From these experiments, we provide novel information regarding potential tumorMDSC synergistic axis involving IL-6 and soluble IL-6R $\alpha$ [see Additional file 1, Figure S12].

MDSCs have been suggested to constitute tumorfavoring microenvironments largely through their suppressive effects on innate and adaptive immunity and 


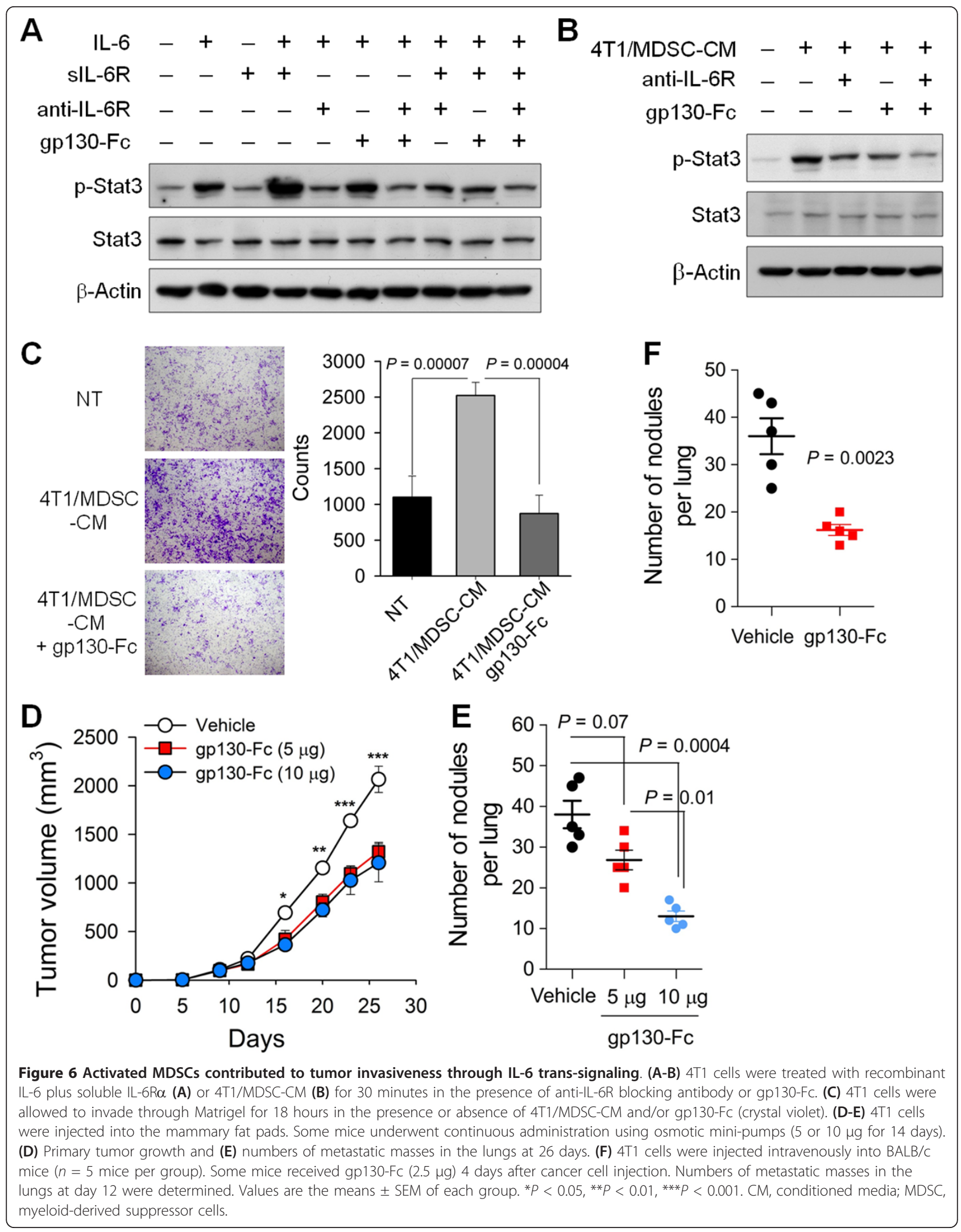




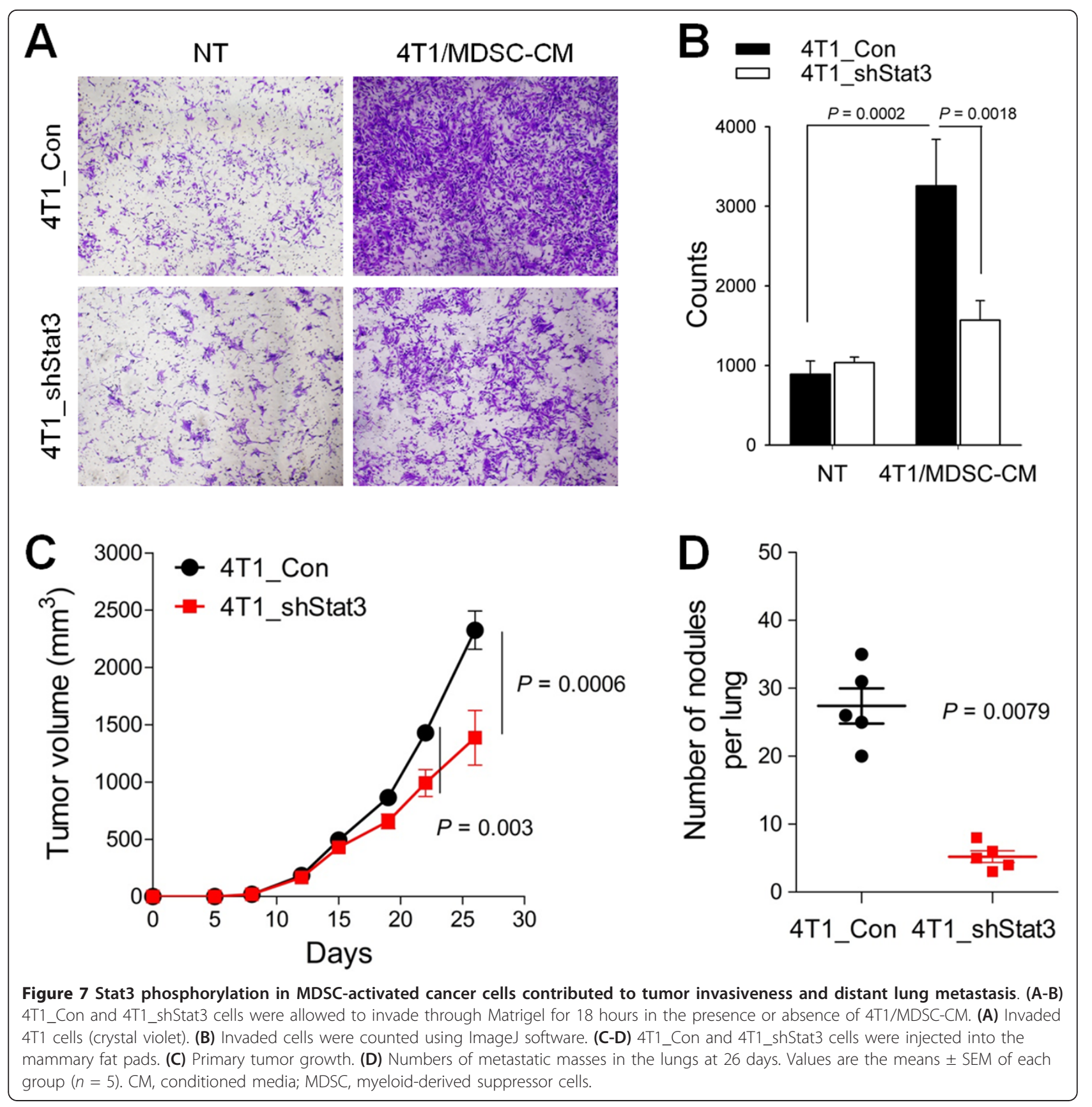

promotion of angiogenesis $[8,9,13,14]$. In our murine breast cancer cell model, 4T1 breast cancer cells recruited more MDSCs and metastasized more strongly compared to EMT6 cells, not only in syngeneic immunocompetent BALB/c mice, but also in immunodeficient NOG mice, in which $\mathrm{T}, \mathrm{B}$, and NK cells are defective (our unpublished data and [27]). This implies that MDSCs in 4T1 cell-bearing mice induced spontaneous distant metastasis of cancer cells independently of their suppressive effects on adaptive and natural-killer cell anti-tumor immunity. Thus, in this study, we provide evidence that MDSCs potentiated by metastasizing breast cancer cells directly enhance the aggressiveness of cancer cells though trans-signaling by upregulating both IL-6 and sIL-6R $\alpha$ secretion in primary tumor sites and the metastatic lung.

Induced expression of IL-6 in EMT6 cancer cells caused recruitment of MDSCs in lymphoid organs, metastatic target organs and primary tumor sites comparable to that caused by metastasizing 4T1 cancer cells, which implies that IL- 6 or downstream signaling may be involved in this process. However, recruitment of 
MDSCs per se was not enough to guarantee that nonmetastasizing breast cancer cells fully adopted metastatic capability. Transfer of splenic MDSCs from metastasizing 4T1 cell-bearing mice increased distant metastasis of non-metastasizing EMT6 cells but did not imbue them with the full metastatic capability of 4T1 cells. Based on the above findings, we assume that additional factors from metastasizing breast cancer cells affected the homing of MDSCs into the tumor sites and increased the potency of recruited MDSCs $[18,19,28,29]$. Our in vitro co-culture experiments showed that recruited MDSCs in the spleens of tumor-bearing mice required additional activation in the vicinity of metastasizing cancer cells, predominantly through contact-independent mechanisms. The outcome of activation of MDSC by metastasizing cancer cells in vitro can be summarized as exaggerated augmentation of IL- 6 production by MDSCs $[18,19]$. Immunofluorescence microscopy of different tissues from 4T1 cell-bearing mice indeed showed that MDSCs in the primary tumor mass and metastatic lung, but not in the spleen, expressed high levels of IL-6. These findings suggest that recruited MDSCs may have different roles or function through different mechanisms depending on the recruited sites (lymphoid organs versus tumor sites, primary or metastatic) [30,31].

In contrast to the requirement for contact with metastasizing cancer cells for increased IL- 6 production by MDSCs, the components necessary for increased soluble IL-6R $\alpha$ production were increased in MDSCs in the remote sites of metastasizing tumor-bearing mice, but not those of non-metastasizing tumor-bearing mice. Expression levels of both IL- $6 \mathrm{R} \alpha$ and the enzymes responsible for digesting the membrane form into soluble forms (Adam10 and Adam17) [25,26,32,33] were increased in the splenic MDSCs of $4 \mathrm{~T} 1$ cell-bearing mice. Moreover, simple cultivation of splenic MDSCs from 4T1 cell-bearing mice increased the expression of soluble IL-6R $\alpha$ compared to EMT6 cell-bearing mice. Thus, at least four remote signals were secreted by metastasizing 4T1 cancer cells; these induced (1) recruitment of MDSCs to various sites of tumor-bearing hosts, (2) increased expression of IL-6R $\alpha$, (3) increased expression of Adam family proteases, and (4) highly increased expression of IL- 6 by MDSCs [34,35,18,19,29]. Further studies are needed to clarify the critical roles of the various mediators that may be involved in MDSC modulation. In this study, we convincingly demonstrated that 4T1 cells responded to IL- 6 trans-signaling by MDSCs. However, as we did not perform experiments specifically inhibiting expression of IL-6 and sIL-6R $\alpha$ in MDSCs in vivo, we cannot absolutely rule out the possibilities that IL-6 and sIL-6R $\alpha$ responsible for metastasis could potentially be coming from other cell types in vivo either the tumor cells themselves or other cells within the tumor microenvironment. Further studies are needed to clarify this aspect.

The importance of IL- 6 signaling in promoting tumorigenesis is well-documented, particularly for tumors associated with chronic inflammation such as colitis-associated colon cancer, pancreatic cancer and hepatocellular carcinoma [36-39]. In addition to these tumors, increased IL-6 signaling is preferentially found in basal-like breast cancers and high-grade tumors and is associated with a poor response to chemotherapy, increased distant metastasis in xenograft animal models and decreased metastasis-free survival in patients $[5,6]$. Thus, IL-6 signaling has been linked to tumor aggressiveness, including cancer stem cell phenotypes [5,6,40,41] and EMT phenotypes [42], drug resistance [43], and anoikis resistance, that is, contactindependent survival, which is required for travel through the vascular system [44]. In addition to tumor-derived IL-6 autocrine signaling [5,6], paracrine IL-6 signaling within tumor microenvironments has been highlighted recently. Mesenchymal stem cells constitute the cancer stem cell niche by providing IL- 6 and CXCL7 $[45,46]$. Paracrine IL-6 signaling from tumor-infiltrating inflammatory cells is more important because these cells have a greater inflammatory cytokine secretion capacity, including IL-6 [47-49]. The caveat for this paracrine signaling is that cancer cells should express sufficient receptor machineries to recognize the increased IL- 6 supply from the microenvironments. In this way, aggressive breast cancer cells exploited a trans-signaling mechanism by inducing the expression of molecules responsible for production of soluble IL-6 receptors (Adam proteases) from the recruited inflammatory cells [50]. In terms of STAT3 signaling as a downstream of IL-6, previous reports suggested that knocking down STAT3 using the shRNA technique in $4 \mathrm{~T} 1$ cells leads to decreased invasiveness of the cells in vitro [51]. The differences between this report and our current study may lie in the perfectness of STAT3 knockdown considering the total absence of phosphorylated STAT3 in the previous report compared to our current study (our unpublished data).

The site of MDSC function in the metastatic tumorbearing mice requires further comment. In terms of sites of MDSC immunosuppressive activity, the available data are contradictory. Some authors suggest that lymphoid organs, including the liver, are the primary sites of MDSC accumulation and immunosuppression $[30,52]$, while others emphasized effector sites, such as inflammatory sites and tumors, but not lymphoid organs, such as the spleen $[31,53,29]$. In terms of MDSC function during the efferent phase of tumor metastasis and related angiogenesis, accumulation of MDSCs in the lung, a metastatic target organ, supported the effective engraftment of metastatic tumor cells at this site $[15,19,54]$. Because the metastasis-promoting effects of 
MDSCs in this study occurred in the absence of adaptive immunity and natural-killer cell activity and there was no increase in IL-6 signaling in the spleen, MDSCs themselves must have directly increased tumor cell metastatic capability in the tumor sites, either primary tumors or metastases, but not in the lymphoid organs, affecting both the afferent and efferent phases of metastasis through exaggerated IL-6 trans-signaling. Lastly, although we clearly showed the direct effects of MDSCs on the in vitro invasiveness and effector phase of lung metastasis, the co-occurrence of reduction in the primary tumor size and metastasis in some experiments prevented us to totally rule out the possibilities that differences in metastasis might be due to differences in tumor size rather than specific effects of MDSCs on metastatic capacity.

\section{Conclusions}

Our findings reveal that breast cancer cells and MDSCs form a synergistic mutual feedback loop and that thuspotentiated MDSCs directly affect breast cancer cell aggressiveness, leading to spontaneous metastasis. We have shown that more MDSCs were recruited to the different organs of mice implanted in the mammary fat pads with high IL-6-producing breast cancer cells and the depletion of MDSCs by an anti-Gr1 antibody reduced the numbers of metastatic nodules in the lung. Moreover, it was shown that when MDSCs were exposed to conditioned media of metastasizing cancer cells, MDSCs secreted exaggerated IL- 6 and soluble IL-6R $\alpha$, which induced persistent activation of STAT3 in cancer cells. ADAM family proteases responsible for the shedding of IL-6R $\alpha$ were also increased on metastasizing cancerexpanded MDSCs. Furthermore, we confirmed that IL-6 trans-signaling was an important mechanism supported by tumor-infiltrating MDSCs to drive the metastatic behavior of cancer cells in vitro and in vivo.

\section{Additional material}

Additional file 1: Figure S1. IL-6 levels in culture supernatants of cancer cells, as determined by ELISA. Figure S2. EMT6 and 4T1 cells were injected into the mammary fat pads of BALB/C mice. The percentages of MDSCs $\left(\mathrm{CD} 11 \mathrm{~b}^{+} \mathrm{Gr}-1^{+}\right)$at 19 days were analyzed by flow cytometry $(n=$ 4). Figure S3. (A) IL-6 was overexpressed on EMT6 cells and IL-6 levels in culture supernatant of selected clone was determined by ELISA. (B) EMT6_Con and EMT6_IL-6 cells were injected into the mammary fat pads of BALB/C mice. MDSCs were analyzed at 21 days $(n=6)$. Figure $\mathbf{S 4}$. Splenic MDSCs from naive and tumor-bearing mice were treated with EMT6-CM, 4T1-CM, or recombinant IL-6 (1 ng/ml) for 6 hours. IL-6 mRNA expression in 4T1-CM-treated splenic MDSCs was detected by RT-PCR. Figure S5. Splenic MDSCs from 4T1 cell-bearing mice treated with 4T1CM for the indicated periods of time. Signaling molecules were detected by Western blotting. Figure $\mathbf{S 6}$. Immunofluorescence staining of Gr-1 (red) and IL-6 (green) in the spleen and tumor of EMT6 cell-bearing mice. Scale bar $=30 \mu \mathrm{m}$ (original magnification, $\times 1,000$ ). Figure S7. 4T1 cells were treated with $4 \mathrm{T1}-\mathrm{CM}$ for the indicated periods of time.
Phosphorylated STAT3 were detected by Western blotting. Figure S8. Soluble IL-6R $\alpha$ levels in culture supernatants of $4 \mathrm{~T} 1$ cells were measured by ELISA. Figure S9. TAPI-2 $(100 \mu \mathrm{M})$ or Protease inhibitors cocktail (3x) were applied to cultures of splenic MDSCs from 4T1 cell-bearing mice for 18 hours. (A) Membrane-bound IL-6Ro was detected by FACS and (B) soluble IL-6R $\alpha$ levels were measured by ELISA. Figure S10. (A) Immunofluorescence staining of Gr-1 (red) and IL-6R ( green) in spleen, tumor, and lung tissues from 4T1 cell-bearing mice. (B) Immunofluorescence staining of Gr-1 (red) and IL-6R $\alpha$ (green) in spleen from EMT6 cell-bearing mice. (C) Immunofluorescence staining of Gr-1 (red) and Adam17 (green) in spleen from 4T1- and EMT6 cell-bearing mice. Scale bar $=30 \mu \mathrm{m}$. Figure S11. Stat3-knockdown 4T1 cells (4T1_shSTAT3 cells) generated using the lentiviral vector containing the short hairpin RNA. STAT3 expression was detected by Western blotting assay. Figure $\mathbf{S 1 2}$.

\section{Abbreviations}

Adam: a disintegrin and metalloprotease; BA: bovine serum albumin; CM: conditioned media; CTL: cytotoxic T cell; ELISA: enzyme-linked immunosorbent assay; EMT: epithelial-to-mesenchymal transition; FACS: fluorescence-activated cell sorting; H \& E: hematoxylin and eosin; IL-6: interleukin-6; MDSC: myeloid-derived suppressor cells; NOG: NOD/scid/LL-2RY chain-deficient; PBS: phosphate-buffered saline; PCR: polymerase chain reaction; PFA: paraformaldehyde; shRNA: short hairpin RNA; STAT3: signal transducer and activator of transcription 3; TCR: T cell receptor.

\section{Competing interests}

The authors declare that they have no competing interests.

\section{Authors' contributions}

$\mathrm{KO}$ designed the research, performed the experiments, interpreted the data and wrote the manuscript; OYL performed most of the experiments; SYS, ON and PMR conducted RT-PCR and immunohistochemistry experiments; MWS generated the animal models; DSL designed the research, interpreted the data, wrote and edited the manuscript. All authors read and approved the final manuscript.

\section{Acknowledgements}

This work was supported by grants from the National R\&D Program for Cancer Control, Ministry of Health \& Welfare (12202001), Basic Science Research Program through the National Research Foundation of Korea (NRF) funded by the Ministry of Education, Science and Technology (2012008122), and the National Research Foundation of Korea (NRF) grant funded by the Korea government (MEST) (2012014152).

\section{Authors' details}

'Laboratory of Immunology and Cancer Biology, Department of Biomedical Sciences, Seoul National University College of Medicine, 103 Daehak-ro Jongno-gu, Seoul 110-799, Republic of Korea. ${ }^{2}$ Interdisciplinary Program of Cancer Biology, Cancer Research Institute, Seoul National University College of Medicine, 103 Daehak-ro Jongno-gu, Seoul 110-799, Republic of Korea.

${ }^{3}$ Transplantation Research Institute, Seoul National University College of Medicine, 103 Daehak-ro Jongno-gu, Seoul 110-799, Republic of Korea.

Received: 21 October 2012 Revised: 20 May 2013

Accepted: 10 September 2013 Published: 10 September 2013

\section{References}

1. American Cancer Society: Breast Cancer Facts \& Figures 2011-2012.[http:// www.cancer.org/Research/CancerFactsFigures/BreastCancerFactsFigures].

2. Hornberger J, Alvarado MD, Rebecca C, Gutierrez HR, Yu TM, Gradishar WJ: Clinical validity/utility, change in practice patterns, and economic implications of risk stratifiers to predict outcomes for early-stage breast cancer: a systematic review. J Natl Cancer Inst 2012, 104:1068-1079.

3. El Saghir NS, Tfayli A, Hatoum HA, Nachef Z, Dinh P, Awada A: Treatment of metastatic breast cancer: state-of-the-art, subtypes and perspectives. Crit Rev Oncol Hematol 2011, 80:433-449.

4. Fidler IJ: The pathogenesis of cancer metastasis: the 'seed and soil' hypothesis revisited. Nat Rev Cancer 2003, 3:453-458. 
5. Oh K, Ko E, Kim HS, Park AK, Moon HG, Noh DY, Lee DS: Transglutaminase 2 facilitates the distant hematogenous metastasis of breast cancer by modulating interleukin-6 in cancer cells. Breast Cancer Res 2011, 13:R96.

6. Sansone P, Storci G, Tavolari S, Guarnieri T, Giovannini C, Taffurelli M, Ceccarelli C, Santini D, Paterini P, Marcu KB, Chieco P, Bonafè M: IL-6 triggers malignant features in mammospheres from human ductal breast carcinoma and normal mammary gland. J Clin Invest 2007, 117:3988-4002.

7. Gabrilovich DI, Nagaraj S: Myeloid-derived suppressor cells as regulators of the immune system. Nat Rev Immunol 2009, 9:162-174.

8. Gabrilovich DI, Ostrand-Rosenberg S, Bronte V: Coordinated regulation of myeloid cells by tumours. Nat Rev Immunol 2012, 12:253-268.

9. Marigo I, Dolcetti L, Serafini P, Zanovello P, Bronte V: Tumor-induced tolerance and immune suppression by myeloid derived suppressor cells. Immunol Rev 2008, 222:162-179.

10. Nagaraj S, Schrum AG, Cho HI, Celis E, Gabrilovich DI: Mechanism of T cell tolerance induced by myeloid-derived suppressor cells. J Immunol 2010, 184:3106-3116.

11. Rodriguez PC, Ochoa AC: Arginine regulation by myeloid derived suppressor cells and tolerance in cancer: mechanisms and therapeutic perspectives. Immunol Rev 2008, 222:180-191.

12. Tu S, Bhagat G, Cui G, Takaishi S, Kurt-Jones EA, Rickman B, Betz KS, PenzOesterreicher M, Bjorkdahl O, Fox JG, Wang TC: Overexpression of interleukin-1 beta induces gastric inflammation and cancer and mobilizes myeloid-derived suppressor cells in mice. Cancer Cell 2008, 14:408-419.

13. Montero AJ, Diaz-Montero CM, Kyriakopoulos CE, Bronte V, Mandruzzato S: Myeloid-derived suppressor cells in cancer patients: a clinical perspective. J Immunother 2012, 35:107-115.

14. Sinha P, Clements VK, Ostrand-Rosenberg S: Interleukin-13-regulated M2 macrophages in combination with myeloid suppressor cells block immune surveillance against metastasis. Cancer Res 2005, 65:11743-11751.

15. Hiratsuka S, Watanabe A, Aburatani H, Maru Y: Tumour-mediated upregulation of chemoattractants and recruitment of myeloid cells predetermines lung metastasis. Nat Cell Biol 2006, 8:1369-1375.

16. Kim S, Takahashi H, Lin WW, Descargues P, Grivennikov S, Kim Y, Luo JL, Karin M: Carcinoma-produced factors activate myeloid cells through TLR2 to stimulate metastasis. Nature 2009, 457:102-106.

17. Yan HH, Pickup M, Pang Y, Gorska AE, Li Z, Chytil A, Geng Y, Gray JW, Moses $H L$, Yang L: Gr-1+CD11b+ myeloid cells tip the balance of immune protection to tumor promotion in the premetastatic lung. Cancer Res 2010, 70:6139-6149.

18. Chalmin F, Ladoire S, Mignot G, Vincent J, Bruchard M, Remy-Martin JP, Boireau W, Rouleau A, Simon B, Lanneau D, De Thonel A, Multhoff G, Hamman A, Martin F, Chauffert B, Solary E, Zitvogel L, Garrido C, Ryffel B, Borg C, Apetoh L, Rébé C, Ghiringhelli F: Membrane-associated Hsp72 from tumor-derived exosomes mediates STAT3-dependent immunosuppressive function of mouse and human myeloid-derived suppressor cells. J Clin Invest 2010, 120:457-471.

19. Deng J, Liu Y, Lee H, Herrmann A, Zhang W, Zhang C, Shen S, Priceman SJ, Kujawski M, Pal SK, Raubitschek A, Hoon DS, Forman S, Figlin RA, Liu J, Jove R, YU H: S1PR1-STAT3 signaling is crucial for myeloid cell colonization at future metastatic sites. Cancer Cell 2012, 21:642-654.

20. Diaz-Montero CM, Salem ML, Nishimura MI, Garrett-Mayer E, Cole DJ, Montero AJ: Increased circulating myeloid-derived suppressor cells correlate with clinical cancer stage, metastatic tumor burden, and doxorubicin-cyclophosphamide chemotherapy. Cancer Immunol Immunother 2009, 58:49-59.

21. Ohki S, Shibata M, Gonda K, Machida T, Shimura T, Nakamura I, Ohtake T, Koyama Y, Suzuki S, Ohto H, Takenoshita S: Circulating myeloid-derived suppressor cells are increased and correlate to immune suppression, inflammation and hypoproteinemia in patients with cancer. Oncol Rep 2012, 28:453-458.

22. Yang J, Mani SA, Donaher JL, Ramaswamy S, Itzykson RA, Come C, Savagner P, Gitelman I, Richardson A, Weinberg RA: Twist, a master regulator of morphogenesis, plays an essential role in tumor metastasis. Cell 2004, 117:927-939.

23. Oh K, Park HB, Byoun OJ, Shin DM, Jeong EM, Kim YW, Kim YS, Melino G, Kim IG, Lee DS: Epithelial transglutaminase 2 is needed for $T$ cell interleukin-17 production and subsequent pulmonary inflammation and fibrosis in bleomycin-treated mice. J Exp Med 2011, 208:1707-1719.
24. Chalaris A, Garbers C, Rabe B, Rose-John S, Scheller J: The soluble interleukin 6 receptor: generation and role in inflammation and cancer. Eur J Cell Biol 2011, 90:484-494.

25. Chalaris A, Rabe B, Paliga K, Lange H, Laskay T, Fielding CA, Jones SA, RoseJohn S, Scheller J: Apoptosis is a natural stimulus of IL6R shedding and contributes to the proinflammatory trans-signaling function of neutrophils. Blood 2007, 110:1748-1755.

26. Arndt PG, Strahan B, Wang Y, Long C, Horiuchi K, Walcheck B: Leukocyte ADAM17 regulates acute pulmonary inflammation. PLoS One 2011, 6 : e19938.

27. Ito M, Hiramatsu H, Kobayashi $K$, Suzue K, Kawahata M, Hioki K, Ueyama $Y$, Koyanagi Y, Sugamura K, Tsuji K, Heike T, Nakahata T: NOD/SCID/gamma(c) (null) mouse: an excellent recipient mouse model for engraftment of human cells. Blood 2002, 100:3175-3182.

28. van Deventer HW, Burgents JE, Wu QP, Woodford RM, Brickey WJ, Allen IC, McElvania-Tekippe E, Serody JS, Ting JP: The inflammasome component NLRP3 impairs antitumor vaccine by enhancing the accumulation of tumor-associated myeloid-derived suppressor cells. Cancer Res 2010, 70:10161-10169.

29. Corzo CA, Condamine T, Lu L, Cotter MJ, Youn Jl, Cheng P, Cho HI, Celis E, Quiceno DG, Padhya T, McCaffrey TV, McCaffrey JC, Gabrilovich DI: HIF-1a regulates function and differentiation of myeloid-derived suppressor cells in the tumor microenvironment. J Exp Med 2010, 207:2439-2453.

30. Ilkovitch D, Lopez DM: The liver is a site for tumor-induced myeloidderived suppressor cell accumulation and immunosuppression. Cancer Res 2009, 69:5514-5521.

31. Haverkamp JM, Crist SA, Elzey BD, Cimen C, Ratliff TL: In vivo suppressive function of myeloid-derived suppressor cells is limited to the inflammatory site. Eur J Immunol 2011, 41:749-759.

32. Chalaris A, Gewiese J, Paliga K, Fleig L, Schneede A, Krieger K, Rose-John S, Scheller J: ADAM17-mediated shedding of the IL6R induces cleavage of the membrane stub by gamma-secretase. Biochim Biophys Acta 2010, 1803:234-245.

33. Briso EM, Dienz O, Rincon M: Cutting edge: soluble IL-6R is produced by IL-6R ectodomain shedding in activated CD4 T cells. J Immunol 2008, 180:7102-7106.

34. Gallina G, Dolcetti L, Serafini P, De Santo C, Marigo I, Colombo MP, Basso G, Brombacher F, Borrello I, Zanovello P, Bicciato S, Bronte V: Tumors induce a subset of inflammatory monocytes with immunosuppressive activity on CD8+ T cells. J Clin Invest 2006, 116:2777-2790.

35. Barsoum IB, Hamilton TK, Li X, Cotechini T, Miles EA, Siemens DR, Graham $\mathrm{CH}$ : Hypoxia induces escape from innate immunity in cancer cells via increased expression of ADAM10: role of nitric oxide. Cancer Res 2011, 71:7433-7441.

36. Bollrath J, Phesse TJ, von Burstin VA, Putoczki T, Bennecke M, Bateman T, Nebelsiek T, Lundgren-May T, Canli O, Schwitalla S, Matthews V, Schmid RM, Kirchner T, Arkan MC, Ernst M, Greten FR: gp130-mediated Stat3 activation in enterocytes regulates cell survival and cell-cycle progression during colitis-associated tumorigenesis. Cancer Cell 2009, 15:91-102.

37. Grivennikov S, Karin E, Terzic J, Mucida D, Yu GY, Vallabhapurapu S, Scheller J, Rose-John S, Cheroutre H, Eckmann L, Karin M: IL-6 and Stat3 are required for survival of intestinal epithelial cells and development of colitis-associated cancer. Cancer Cell 2009, 15:103-113.

38. Lang SA, Moser C, Gaumann A, Klein D, Glockzin G, Popp FC, Dahlke MH, Piso P, Schlitt HJ, Geissler EK, Stoeltzing O: Targeting heat shock protein 90 in pancreatic cancer impairs insulin-like growth factor-I receptor signaling, disrupts an interleukin-6/signal-transducer and activator of transcription 3/hypoxia-inducible factor-1alpha autocrine loop, and reduces orthotopic tumor growth. Clin Cancer Res 2007, 13:6459-6468.

39. Park EJ, Lee JH, Yu GY, He G, Ali SR, Holzer RG, Osterreicher CH, Takahashi $H$, Karin M: Dietary and genetic obesity promote liver inflammation and tumorigenesis by enhancing IL-6 and TNF expression. Cell 2010, 140:197-208.

40. Korkaya H, Liu S, Wicha MS: Regulation of cancer stem cells by cytokine networks: attacking cancer's inflammatory roots. Clin Cancer Res 2011, 17:6125-6129.

41. Korkaya H, Liu S, Wicha MS: Breast cancer stem cells, cytokine networks, and the tumor microenvironment. J Clin Invest 2011, 121:3804-3809.

42. Yadav A, Kumar B, Datta J, Teknos TN, Kumar P: IL-6 promotes head and neck tumor metastasis by inducing epithelial-mesenchymal transition 
via the JAK-STAT3-SNAIL signaling pathway. Mol Cancer Res 2011, 9:1658-1667.

43. Wang Y, Niu XL, Qu Y, Wu J, Zhu YQ, Sun WJ, Li LZ: Autocrine production of interleukin- 6 confers cisplatin and paclitaxel resistance in ovarian cancer cells. Cancer Lett 2010, 295:110-123.

44. Wang Y, Li L, Guo X, Jin X, Sun W, Zhang X, Xu RC: Interleukin-6 signaling regulates anchorage-independent growth, proliferation, adhesion and invasion in human ovarian cancer cells. Cytokine 2012, 59:228-236.

45. Sasser AK, Sullivan NJ, Studebaker AW, Hendey LF, Axel AE, Hall BM: Interleukin-6 is a potent growth factor for ER-a-positive human breast cancer. FASEB J 2007, 21:3763-3770

46. Liu S, Ginestier C, Ou SJ, Clouthier SG, Patel SH, Monville F, Korkaya H, Heath A, Dutcher J, Kleer CG, Jung Y, Dontu G, Taichman R, Wicha MS: Breast cancer stem cells are regulated by mesenchymal stem cells through cytokine networks. Cancer Res 2011, 71:614-624.

47. Lesina M, Kurkowski MU, Ludes K, Rose-John S, Treiber M, Klöppel G, Yoshimura A, Reindl W, Sipos B, Akira S, Schmid RM, Algül H: Stat3/Socs3 activation by IL-6 transsignaling promotes progression of pancreatic intraepithelial neoplasia and development of pancreatic cancer. Cancer Cell 2011, 19:456-469.

48. Lo CW, Chen MW, Hsiao M, Wang S, Chen CA, Hsiao SM, Chang JS, Lai TC, Rose-John S, Kuo ML, Wei LH: IL-6 trans-signaling in formation and progression of malignant ascites in ovarian cancer. Cancer Res 2011, 71:424-434.

49. Matsumoto S, Hara T, Mitsuyama K, Yamamoto M, Tsuruta O, Sata M, Scheller J, Rose-John S, Kado S, Takada T: Essential roles of IL-6 transsignaling in colonic epithelial cells, induced by the IL-6/soluble-IL-6 receptor derived from lamina propria macrophages, on the development of colitis-associated premalignant cancer in a murine model. J Immunol 2010, 184:1543-1551.

50. Chen Q, Fisher DT, Clancy KA, Gauguet JM, Wang WC, Unger E, RoseJohn S, von Andrian UH, Baumann H, Evans SS: Fever-range thermal stress promotes lymphocyte trafficking across high endothelial venules via an interleukin 6 trans-signaling mechanism. Nat Immunol 2006, 7:1299-1308.

51. Ling X, Arlinghaus RB: Knockdown of STAT3 expression by RNA interference inhibits the induction of breast tumors in immunocompetent mice. Cancer Res 2005, 65:2532-2536.

52. Watanabe S, Deguchi $K$, Zheng R, Tamai H, Wang LX, Cohen PA, Shu S: Tumor-induced $\mathrm{CD} 11 \mathrm{~b}+\mathrm{Gr}-1+$ myeloid cells suppress $\mathrm{T}$ cell sensitization in tumor-draining lymph nodes. J Immunol 2008, 181:3291-3300.

53. Lesokhin AM, Hohl TM, Kitano S, Cortez C, Hirschhorn-Cymerman D, Avogadri F, Rizzuto GA, Lazarus JJ, Pamer EG, Houghton AN, Merghoub T, Wolchok JD: Monocytic CCR2(+) myeloid-derived suppressor cells promote immune escape by limiting activated CD8 T-cell infiltration into the tumor microenvironment. Cancer Res 2012, 72:876-886.

54. Acharyya S, Oskarsson T, Vanharanta S, Malladi S, Kim J, Morris PG, ManovaTodorova K, Leversha M, Hogg N, Seshan VE, Norton L, Brogi E, Massagué J: A CXCL1 paracrine network links cancer chemoresistance and metastasis. Cell 2012, 150:165-178.

doi: $10.1186 /$ bcr3473

Cite this article as: Oh et al:: A mutual activation loop between breast cancer cells and myeloid-derived suppressor cells facilitates spontaneous metastasis through IL-6 trans-signaling in a murine model. Breast Cancer Research 2013 15:R79.

\section{Submit your next manuscript to BioMed Central and take full advantage of:}

- Convenient online submission

- Thorough peer review

- No space constraints or color figure charges

- Immediate publication on acceptance

- Inclusion in PubMed, CAS, Scopus and Google Scholar

- Research which is freely available for redistribution 